\title{
Reforma agraria con orientación de mercado
}

\author{
Alfonso Goitia
}

\section{Introduccion}

En los distintos paises de Centro América las experiencias de procesos de Reforma Agraria se han ido desarrollando desde principios de de la década de los cincuenta, en general estos procesos han pretendido resolver el problema de la tenencia de la tierra y especlficamente el acceso del campesino a ésta. Las diferentes modalidades adoptadas han estado en función de redistribuir la propiedad de la tierra, de controlar la generación y distribución del excedente en el agro; de modernizar las relaciones de trabajo en el campo y para contrarestar el ascenso del movimiento popular. (Pelupessy, W. 1989).

En las últimas dos décadas las reformas agrarias impulsadas en Honduras a mediados de los setenta, asl como a principios de los ochenta en El Salvador y Nicaragua han tenido un impacto importante en relación al acceso a la tierra al campesino, las formas adoptadas en estos palses han sido diversas desde la conformación de estructuras productivas cooperativizadas, la difución de unidades parcelarias y el establecimiento de propiedades estatizadas.

En los últimos anos como resultado de la crisis económica que afectó las economlas de la región y especialmente la agricultura, los procesos de reforma agraria basados en los mecanismos de expropiación y en la conformación de estructuras colectivas o cooperativas de producción, están siendo duramente criticadas como formas pocn eficientes de organización de la producción, debido a las limitaciones y debilidades que presentan en términos de productividad asl como de funcionamiento, de tal forma que actualmente están siendo asumidos nuevos mecanismos de acceso a la tierra por la vla de la titulación o del mercado de tierras. 
La mayor importancia que cobran estos mecanismos de acceso a la tierra en la década de los echenta en distintos paises de la región, hace necesario establecer el efectivo impacto que tendrán, asi como la incidencia que sobre las formas cooperativas de producción puedan tener, especialmente en el caso de El Salvador.

En este sentido podemos afirmar que la reorientación de las reformas agrarias a través de los mecanismos del mercado bien pueden suponer un relativo acceso a la tierra al campesino, pero se sustentan en un objetivo de mayor alcance que pretende romper con las posibilidades 0 potencialidades de las formas cooperativas o colectivas de producción en función de la supuesta eficiencia y la óptima asignación que el mercado puede establecer sobre la tierra y su uso.

Por lo tanto, en este estudio pretendemos establecer el desarrollo que han tenido estos mecanismos de titulación y mercado de tierras en la región y más específicamente en Honduras y El Salvador; asl como el impacto que tienen sobre las formas cooperativas de producción; además trataremos de identificar algunas vias para el fortalecimiento de estas formas de organización de la producción.

\section{Los procesos de reforma agrarla en Centroamérica}

Las reformas agrarias consideradas desde el ámbito de la afectación de tierras, de la redistribución de éstas y del número de beneficiarios, han sido limitadas; los impactos en cada pais de la región son diferentes debido a las caracteristicas específicamente adoptadas y a la forma como se desarrollan en sus propios contextos históricos.

La reforma agraria de Jacobo Arbenz en Guatemala en 1952, marca el inicio de los impactos que estos procesos tendrán en Centro América en términos de acceso a la tierra, cobertura y beneficiarios. Si bien se considera que esta reforma tenia como "intensión consolidar la vla farmer del desarrollo capitalista en el campo, bajo presión campesina. Esta habla repartido la cuarta parte de las tierras de fincas de procedencia privada y pública". (Pelupessy, W. 1989), y beneficiando al $23 \%$ de la PEA Agropecuaria.

Para otros esta primera reforma agraria "habla incorporado cerca del $34 \%$ de la superticie en fincas..., beneficiando al $33 \%$ del campesinado en los moldes de un proyecto de expansión del capitalismo en el agro que descartaba la fracción terrateniente más atrasada, a la vez que buscaba potenciar una capa de nuevos capitalistas y profundizar el desarrollo mercantil del campesinado". (Baumeister, E. 1987).

Este importante proceso fue revertido en 1954 posibilitando la devo- 
Cuadro No. 1

Impacto de las reformas agrarias en Centroamérica

\begin{tabular}{|c|c|c|c|c|c|c|c|}
\hline \multirow[t]{2}{*}{ País } & \multicolumn{3}{|c|}{$\%$ de tierra \% } & \multicolumn{3}{|c|}{ PERA agropecuaria } & \multirow{2}{*}{ Período } \\
\hline & Total & $\begin{array}{l}\text { Colec- } \\
\text { tiva (1) }\end{array}$ & $\begin{array}{l}\text { Indivi- } \\
\text { dual (2) }\end{array}$ & Total & $\begin{array}{c}\text { Colec- } \\
\text { tiva }\end{array}$ & $\begin{array}{l}\text { Indivi- } \\
\text { dual }\end{array}$ & \\
\hline $\begin{array}{l}\text { Costa Rica } \\
\text { El Salvado } \\
\text { Guatemala } \\
\text { (Guatemala) } \\
\text { Honduras } \\
\text { Nicaragua }\end{array}$ & $\begin{array}{c}6 \\
26 \\
16 \\
(27) \\
12 \\
36\end{array}$ & 19 & 10 & $\begin{array}{c}22 \\
8 \\
(23) \\
9 \\
48\end{array}$ & $\begin{array}{r}3 \\
20\end{array}$ & $\begin{array}{r}3 \\
15\end{array}$ & $\begin{array}{c}1963-85 \\
1976-86 \\
1955-82 \\
(1952-54) \\
1963-85 \\
1979-86\end{array}$ \\
\hline
\end{tabular}

Fuente:: Baumeister, E.: Tendencias de la agricultura centroamericana en los años ochenta; San José 1987, p.42.

- Barraclough, S. y Scotr M.: The rich have already eaten; Amsterdam 1987, p.98,100.

Inforpress: Resurge problema de la tierra en Guatemala; Guatemala, 19-6-1986.

Nota: (1) Estatal y/o de cooperativas de producción.

(2) Incluyendo cooperativas de servicio.

lución de un $62 \%$ de las tierras distribuidas y por lo tanto limitando seriamente sus alcances iniciales; de tal forma que hacia 1982 sólo un $16 \%$ de la tierra ha sido afectada y beneficiada un $8 \%$ de la población económicamente activa del agro.

En el caso de Honduras el proceso se desarrolla en la década de los setenta influenciado por la "Alianza para el Progreso", se considera que para 1985 un $12 \%$ de la superticie en fincas fue afectada, beneficiando a un $9 \%$ de la PEA agropecuaria. Según la información básica de los gnupos campesinos de la reforma agraria en 1985 existlan 1941 grupos, con un área adjudicada de 294,422 ha. de las cuales 215,136 ha. son cultivables; los socios actuales son de 48,129 de un número inicial de 61,176 . Una de las caracter/sticas importantes del proceso de reforma agraria en Honduras fue su capacidad de organización campesina la cual aglutinaba a cerca del $25 \%$ de la PEA rural. En los últimos anos "el sector reformado no llega a comprender ni al 10\% de la PEA agropecuaria y las grandes cooperativas dedicadas a cultivos intensivos no agnupa a más del 3\% del campesinado". (Baumaister, E. 1987).

En Costa Rica el impacto de la reforma agraria fue aun más limitado que en el resto de paises de Centro América afectando solo el $6 \%$ de la lierra y beneficiando a un 3\% de la PEA agropecuaria entre 1963-1985. 
"A comienzos de los anos 70 aumentaron las acciones y ocupaciones de tierras bajo la creciente presión del campesinado sin tierra, con la presidencia de Daniel Oduber (1974-78) se aceleró el proceso de expropiación con compensación y la distribución a los beneficiarios" ( $\mathrm{Pe}$ lupessy, W. 1989). En la década de los ochenta el proceso de reforma al igual que en Honduras adopta la característica de extensión de títulos de propiedad privada.

En Nicaragua el impacto de la reforma agraria en 1979 habla incorporado el $36 \%$ de la tierra agrícola y beneficiado al $48 \%$ de la PEA agropecuaria, los mecanismos utilizados fueron la confiscación de tierras se Somoza, su familia y allegados lo cual alcanzó el $14 \%$ de la tierra agropecuaria y el $9 \%$ de PEA rural fue beneficiada; se adjudicaron tierras a cooperativas de producción (CAS) y familias individuales que podian formar cooperativas de servicios de servicios (CCS). En los primeros anos del proceso de reforma agraria asumen mayor importancia las formas colectivas de producción tanto a través de las propiedades estatales como de las cooperativas de producción; a partir de 1986 las adjudicaciones a familias individuales, de tierras no explotadas eficientemente fueron mecanismos que viabilizaron nuevas formas de acceso a la tierra, la adopción de estos mecanismos estaban asociados a factores como "la intensificación de guerra, los problemas económicos (también de las empresas colectivas) y el desarrollo de la UNAC (Organización de Campesinos, Pequefios y Medianos Productores Agropecuarios)." (Pelupessy, W. 1989).

Después de diez años de reforma agraria en Nicaragua "se ha modificado profundamente el perfil de la estructura agraria del país. El sector reformado representa aproximadamente el $28 \%$ de la superticie agropecuaria en fincas, las familias beneficiadas con tierra representan aproximadamente al $43 \%$ de las familias campesinas, si incluimos aquellos que recibieron títulos por las tierras nacionales que ocupaban en la región central y la frontera agrícola, el peso social se eleva al $60 \%$ de las familias campesinas". (Baumeister, E. 1991, p. 50).

En El Salvador el proceso de reforma agraria se inicia en marzo de 1980; aunque un primer intento es el que se trata de impulsar en 1976 con el Primer Distrito de Transformación Agraria, durante la gestión del Presidente A. Molina, el área que debería ser afectada era relativamente limitada 58,744 ha. de las cuales 56,744 ha eran tierras con vocación agrícola, forestal o ganadera pero al final de duras críticas y presiones políticas de los sectores terratenientes más tradicionales, ésta no se lleva a cabo. Pasarian cuatro anos para que la reforma agraria se desarrollara definitivamente; luego de un Golpe de Estado en octubre de 
Cuadro No. 2

Nicaragua: Estructura de tenencla de tlerra (1988) por sectores de propledad

\begin{tabular}{|l|r|r|r|}
\hline Sectores & 1988 & $\%$ & 1978 \\
\hline Privado Individual & & & \\
& & & \\
+ de 500 manzanas & $1,087.149$ & 13.5 & 36.2 \\
$200-500$ manzanas & $1,033.586$ & 12.8 & 16.2 \\
$50-200$ manzanas & $2,293.293$ & 15.1 & 15.4 \\
-10 manzanas & 167.726 & 2.1 & 2.1 \\
& & & \\
Reformado & 984.230 & 11.7 & \\
Area estatal & 921.491 & 11.4 & \\
Coop. de Producción & 133.620 & 1.7 & \\
Coop. Cred. y Serv. & 23.509 & .3 & \\
Colec. de Trabajo & 37.060 & .5 & \\
Coop. "Surco muerto" & 209.974 & 2.6 & \\
Asignac. Individuales & $8,073.899$ & 100.1 & 100.1 \\
\hline Total & & \\
\hline
\end{tabular}

Fuente: Baumeister, Eduardo. "Elementos para actualizar la caracterización de la Agricultura Centroamericana"; Cuadro No. 7, p.51.

1979 y de sucesivas Juntas Civiles-Militares. Los objetivos que perseguía la reforma agraria estaban relacionadas a la capacidad de control por parte del Estado en la generación y distribución del excedente del agro, así también tenía fines políticos de contrainsurgencia, capacidad de control del territorio nacional y del movimiento popular en el campo.

Los primeros indicadores muestran que la reforma agraria habría impactado el $26 \%$ de la tierra agrícola y beneficiado a un $22 \%$ de la PEA agropecuaria. El proceso desarrollado en tres fases: La primera impulsada por los Decretos 153 y 154, posibilita la afectación de propiedades mayores a las 500 ha. "expropiando a $\mathbf{4 7 0}$ propietarios de fincas y formándose más de 300 cooperativas de producción; beneficiando al $7 \%$ de la PEA rural y afectando el $19 \%$ de las tierras agropecuaria nacionales (Pelupessy, W. 1989, p. 283). La segunda fase suponía afectar las propiedades de 150 ha. y más, se modificó a partir de la Constitución política del '83, "ésta modalidad habría afectado el $7 \%$ de la superticie en fincas y beneficiado al $15 \%$ de la población nural". (Pelupessy, W. 
1989, p. 283).

En la actualidad el área en el que se desarrolla la reforma agraria ha ido disminuyendo de 373,485 ha. (según Decretos) en 1983 a 282,225 ha. en 1988/89, debido a la aplicación de los derechos de reserva de los antiguos propietarios y al establecimiento de área de reseva nacional. En cuanto al número de beneficiarios éstos suman 81,403 familias en $1988 / 89$ superior en $6 \%$ a las 76,629 familias en 1983 ; esto se debe a la incorporación de nuevos socios a las cooperativas, a la aplicación del Decreto 839 de Transferencia Voluntaria de Tierras y a la reactivación de algunas cooperativas abandonadas por ubicarse en zonas conflictivas a las cuales han sido incorporados población desplazada. Si bien se consideraba que la reforma agraria a sus inicios beneficiarla a 95,200 familias, debido al conjunto de factores adversos al proceso, la cantidad de beneficiarios todavia no logra llegar a los niveles proyectados.

En esta perspectiva se senalaba que la reforma agraria "a pesar que habia beneficiado al $22 \%$ de la población rural $(95,200$ familias) la mayor parte de la población rural continúa viviendo en una situación donde la pobreza y la miseria dominan su vida dia a dia. Este sector que comprendia 200,000 familias sin tierra representan el $51 \%$ de las familias nurales, un incremento del 10\% respecto al porcentaje de 1975" (Misión Interagencial del Sistema de Naciones Unidas. 1986).

\section{Cuadro No. 3 \\ El Salvador}

Area total en que se desarrolla el proceso de reforma agrarla y famillas beneflcladas 1983 y1988/89

\begin{tabular}{|l|r|r|r|r|}
\hline \multirow{2}{*}{ Decretos } & \multicolumn{2}{|c|}{1983} & \multicolumn{2}{c|}{$1988 / 89$} \\
\cline { 2 - 5 } & Area (ha) & Familias & Areas (ha) & Familias \\
\hline Decreto 154 (Fase I) & 222,921 & $26,205(1)$ & $119,107.0$ & $36,558(1)$ \\
Decreto 207 (Fase III) & 80,114 & 50,424 & $54,039.0$ & 42,562 \\
Decreto 842 & 81,450 & & $23,378.2$ & \\
Decreto 838 & - & - & $5,700.9$ & 2,283 \\
Total & 373,485 & 76,629 & $282,225.1$ & 81,403 \\
\hline
\end{tabular}

Fuente: MAG-PERA. Evaluaciones del Proceso de Reforma Agraria.

(1) Incluye beneficiarios del Decreto 154 y 842 . Dado que el Decreto 842 incorpora las tierras propiedad del ISTA antes de la Reforma Agraria a las Cooperativas de producción. 
Los procesos de reforma agraria en Centro América aunque con alcances limitados en relación al nivel de afectación de tierras y al número de beneficiarios, han posibilitado en todo caso el desarrollo de estructuras productivas que pueden tener un potencial importante en la capacidad de organización económica de los campesinos, ciertamente en la década de los setenta el desarrollo organizativo del campesinado en Honduras alcanzó características sin precedentes en América Latina, en el caso de El Salvador el desarrollo organizativo del campesinado vinculado a la reforma agraria y posteriormente vinculado a otros sectores campesinos puede representar la articulación de nuevas estratégias de desarrollo en el agro.

\section{Las cooperativas de producción en Centroamérica}

En la mayoría de los paises de la región, los procesos de reforma agraria han puesto un énfasis importante en las formas cooperativas de producción, esto no quiere decir que fuera del mecanismo de la reforma agraria no se hayan desarrollado cooperativas de producción, especialmente debido al fomento y promoción de éstas por organismos regionales y nacionales vinculados al movimiento cooperativo.

Cuadro No. 4

Cooperativas y asoclados del sector primarlo en Centroamérica

\begin{tabular}{|l|c|c|}
\hline Pais & $\begin{array}{c}\text { Número de } \\
\text { Cooperativas }\end{array}$ & $\begin{array}{c}\text { Número de } \\
\text { Asociados }\end{array}$ \\
\hline Costa Rica & 155 & 48,200 \\
Nicaragua & 3,126 & 77,000 \\
Honduras & 816 & 75,000 \\
Guatemala & 462 & 49,900 \\
El Salvador & 517 & 107,000 \\
\hline
\end{tabular}

Fuente: Comisión de las Comunidades Europeas.

Las cooperativas agrícolas constituyen el $68 \%$ del total de cooperativas de la región, en éstas las cooperativas de producción como formas de explotación colectivas" se han desarrollado en gran parte como producto de la reforma agraria. En el se ubican el $62 \%$ de las cooperativas agricolas de El Salvador, un $80 \%$ en Honduras, un $40 \%$ en Costa Rica y un 36\% en Nicaragua". (Comisión de las Comunidades Europeas. 1988).

Las cooperativas de producción agricolas, especialmente las vinculadas a los procesos de reforma agraria, están siendo sujeto en los últi- 
mos anos a serios cuestinamientos en cuanto a su viabilidad como formas de organización de la producción. las debilidades mostradas en el contexto de la crisis y de sus problemas propios de gestión y funcionamiento están propiciando el desarrollo de mecanismos de transformación, sea por la via de la titulación o del mercado de tierras, para conformarlas en unidades de producción individuales.

Las cooperativas de producción agrícola en El Salvador tienen una signifivativa importancia, de 328 cooperativas existentes en 1988/89 éstas se ubican en 199,486.2 ha. que representan cerca del $11 \%$ del área agricola nacional, pero constituyen más del $37 \%$ de las tierras de las fincas de más de 100 ha.

-As l mismo su contribución a la producción nacional en distintos rubros agricolas no es nada despreciable.

Cuadro No. 5

El Salvador

Porcentaje de particlpaclón de la prlmera etapa

del sector reformado en la superficle y producclón

de granos básicos y productos tradicionales de exportación, con relaclón al nlvel naclonal Ańo 198/1989

\begin{tabular}{|l|c|c|}
\hline Rubros & $\begin{array}{c}\text { Superticie } \\
\text { (\%) }\end{array}$ & $\begin{array}{c}\text { Producción } \\
(\%)\end{array}$ \\
Maiz & 7.5 & 11.2 \\
Arroz & 23.5 & 22.2 \\
Frijol & 10.1 & 5.4 \\
Maicillo & 3.1 & 2.7 \\
Café & 11.5 & 12.8 \\
Cana & 31.5 & 37.8 \\
Algodón & 40.8 & 37.6 \\
\hline
\end{tabular}

Fuente: DGEA. Anuario de Estadísticas Agropecuarias 1988-1989.

PERA. Quinto Censo de las cooperativas de la primera etapa de la Reforma Agraria. 1989.

En el caso de Nicaragua las cooperativas de producción absorben el $11.4 \%$ de la tierra según sectores de propiedad en 1988. (Ver Cuadro No. 2). La adjudicación de tierras en Costa Rica y Honduras en la década de los setenta se orientó hacia las formas cooperativas las cuales tuvieron resultados positivos en cuanto nuevas formas de producción y un potencial productivo importante como nuevas empresas. 
La importancia de las cooperativas agropecuarias se puede percibire por el hecho que éstas articulan al $40 \%$ del más del millón de asociados económicamente activos, la debilidad en cuanto a la información sobre su contribución al Producto Interno Bruto en los distintos paises de la región no permite apreciar la dimensión de su contribución. Pero en las últimas dos décadas el significativo crecimiento de las cooperativas de producción agrícolas especialmente en Honduras, Nicaragua y EI Salvador hacen prever que su aporte en la producción de granos básicos asl como de productos agroexportables tradicionales y no tradicionales tiende a ser relevante. "Existe pues, en el sector agricola un componente de empresas cooperativas que han demostrado una fuerte participación en la producción y una real capacidad de movilización de recursos financieros, humanos y organizativos (entre otros en agroindustria, leche, café, etc.). (Comisión de las Comunidades Europeas, 1988).

\section{III. ¿La segurldad de la tenencla de la tlerra?: tltulaclón y mercado} de tlerras.

Los procesos de titulación y mercado de tierras están cobrando una mayor importancia en los paises de la región en la última década; si bien estos mecanismos suponen una mayor seguridad en la tenencia de la tierra, éstas se articulan a la lógica de los llamados programas de ajuste estructural y privatización. Los cuales pretenden el dominio del mercado en todos los órdenes del quehacer económico; para el caso de la agricultura éstas permitirlan la asignación y el uso más eficiente de la tierra.

El desarrollo más amplio de estos mecanismos de titulación y de mercado de tierras en Honduras y EI Salvador hacen necesario un análisis de sus limitaciones y potencialidades respecto al acceso de la tierra al campesino, asi como a los impactos que tendrian en la organización de la producción y el desarrollo de las organizaciones campesinas.

El desarrollo y fortalecimiento de las organizaciones campesinas, asi como de las formas cooperativas de producción en la agricultura es una de las características más importantes en la última década, en la cual han tenido que ver mucho los procesos de reforma agraria. Pero en la actualidad las estructuras cooperativas y asociativas de producción resultado de dichas reformas, están siendo sometidas a procesos de privatización y parcelación que tenderán a modificar nuevamente la estructura de tenencia de la tierra y organización de la producción en el agro

Es impotante senalar que el concepto de reforma agraria con 
orientación de mercado, está precisamente referido a la tendencia que actualmente se trata de imponer en nuestros paises, como mecanismos únicos y viables de acceso a la tierra, tanto a través del mercado de tierras, 0 el fomento de unidades productivas familiares; no se trata en este caso de desestimar las potencialidades que estas puedan tener, pero creemos que en el marco de una realidad agraria donde domina la pobreza rural donde existen gran cantidad de campesinos sin tierra, donde las políticas agrarias tienen un sesgo desfavorable a los pequefos productores, etc. los alcances de la titulación y mercado de tierras son limitados.

Algunos argumentos a favor de los mecanismos de titulación de tierras están relacionados a: (Fandiño, J.M. 1986. Págs. 1 y 2).

1. La seguridad de tenencia, la cual se refiere a las garantias que el individuo puede adquirir sobre el acceso a la tierra que cultiva a través de la entrega de un título de dominio pleno. Seguridad juridica.

2. La capacidad que brinda el titulo de propiedad a fin de posibilitar la introducción de obras de conservación y mejoras en la tierra, así como inversiones de mediano y largo plazo que incrementen la productividad de la unidad productiva.

3. Evita o aminora los problemas de invasiones y litigios como resultado de los sistemas desorganizados e inseguros de tenencia.

4. Un titulo permite y agiliza las transacciones y contratos comerciales sobre la tierra, de compra, venta, arrendamiento, etc., lo cual está relacionado al mercado de tierras.

5. Evita el fraccionamiento sistemático de generación tras generación, generalmente este tipo de legislación establece limites minimos de fraccionamiento.

6. La posesión de título de propiedad y la seguridad de tenencia deberá repercutir en un mayor acceso al crédito y asi potenciar el desarrollo técnico y productivo de las unidades.

Los argumentos sehalados si bien pueden mostrarnos los beneficios derivados de un proceso de titulación de tierras y especialmente de la conformación de pequenas unidades productoras, éstas chocan con la realidad agraria de los paises de la región, evidenciando sus limites y los impactos que pueden generar en la estructura agraria. Esto lo trataremos más adelante en relación a los casos de Honduras y EI Salvador.

Previamente estableceremos las impenfecciones que presentan los mercados de tierras, como mecanismos de acceso a la tierra. A este 
respecto se senala: Que un mercado de tierras "competitivo requiere que haya unidades de tierra homogéneas, numerosos compradores y vendedores, completa libertad de entrar y salir del mercado..., fácil acceso a la información de transacciones de tierras, incluyendo precios y propuestas". Los problemas que se presentan y que evidencian la imperfección de estos mercados de tierras son:

1. La concentración de la propiedad de la tierra.

2. La falta de demanda efectiva.

3. La complejidad y el costo de los procedimientos legales.

Considerando estos aspectos analizaremos los casos de Honduras y El Salvador en cuanto al desarrollo de estos mecanismos y sus impactos.

\section{Honduras}

En los anos '80, el proceso de titulación a pequenos propietarios ha sido el mecanismos de reforma aplicado con apoyo y financiamiento del AID. "El proyecto de titulación de tierras (PTT) del Instituto Nacional Agrario (INA) ha pretendido entregar títulos de dominio pleno a 70,000 campesinos quienes actualmente poseen explotaciones agropecuarias de menos de 50 ha. en tierras nacionales y ejidales". (Fandino, J.M. 1986). Este proyecto entre $1983-88$ ha emitido 3,540 títulos en un áreas de 222,552 ha.

"La titulación que ha desarrollado el INA, no como parte del PTT, sino a través de su programa normal institucional ha emitido 1,375 títulos que se distribuyen en 380 concedidas a 342 grupos acreditando el traspaso de propiedad de 97,638 ha. y las restantes 995 títulos han sido entregados a unidades familiares individuales resultando un total de 99,576 ha." (Sintesis de la problemática sobre tenencia de la tierra).

En Honduras los procesos de reforma agraria impulsados en los anos setenta que propiciaron la conformación de cooperativas de produción en un amplio desarrollo de organización campesina; muestra en la actualidad un énfasis en el uso del mecanismo de titulación en dos vertientes, una la asignación de títulos a gnupos acreditados y otra a unidades familiares individuales, esıa última forma de titulación es la que cobra mayor importancia ya que considerando el PTT y el Programa Normal del INA se habrian entregado 4,535 títulos en un área de 322,128 ha. más de 3 veces el área titulada de las agnupaciones.

La limitación de esta políticas de titulación como mecanismos de acceso a la tierra se puede apreciar cuando se senala que "existen en el 
pais aproximadamente 125,000 minifundistas tipificadas éstas en la Ley como Fincas menores de 5 ha. Asímismo se consignan un número significativo de campesinos sin tierra de aproximadamente 150,000. A la par coexisten un número relativamente pequeho de aproximadamente 460 propiedades con grandes extensiones de tierras, en la mayoría de los casos abandonadas subutilizadas y a veces fuera de los limites agrarios establecidos en la ley, con tendencia productiva hacia la ganadría extensiva". (Estrategia de Desarrollo del Sector Reformado del INA, 1988).

Otra información nos senala que en Honduras para fines de los ' 80 los campesinos pobres se ubican en el $35 \%$ de fincas pero ocupan tan solo el $4.1 \%$ de la tierra. (Baumeister, E. 1991, p. 25).

Tratamos de identificar que estos procesos de titulación presetan limitaciones a una de los problemas fundamentales del agro de Honduras, que es el acceso a la tierra a una gran cantidad de campesinos que todavía no la poseen. Además la titulación solo habría logrado un $7 \%$ de la meta planteada hasta 1988.

Los problemas de acceso a la tierra son de una dimensión tal en Honduras que "ha forzado a las familias campesinas a trasladarse a las laderas y tierras forestales sembrando granos básicos, café y otros aultivos". (Un perfil de mercado de tierras rurales en Honduras). Además una "reciente evidencia empírica de tres departamentos en Honduras demuestra que $84 \%$ de las parcelas de tierras nacionales delineadas para proyecto de titulación de tierras del Gobierno son ocupadas bajo sistemas de tenencia de la tierra informal. (Barres. 1988, p.94).

Respecto a los argumentos a favor de la titulación el estudio de J.M. Fandino y otros sefala que en términos de seguridad de la tierra el "título como tal no les resuelve ningún problema ya que la propiedad jurídica del Estado del terreno, anteriormente no les representaba ninguna amenaza al ocupante y usuario de la tierra". Así también respecto a las mejoras que podrlan introducir a la tierra son pocos los que pueden desarrollar estas nuevas inversiones y los problemas por el área del terreno no es un problema debido a un conocimiento específico del propietario de dichos terrenos (linderos de lotes).

En cuanto a las posibilidades de entrar al mercado de tierras el estudio senala que los medianos o grandes propietarios de este tipo de terrenos pueden desarrollar transacciones, pero los pequenos productores a pesar de la titulación están sometido a la legislación que prohibe negociaciones de estas pequenas propiedades.

El acceso al crédito a pesar de la titulación encuentra su límite en las 
restricciones que impone el sistema financiero privado. Los pequenos propietarios no llenan las suficientes garantlas para acceder al crédito, salvo que existan otras estructuras institucionales que favorezcan a estos productores en sus posibilidades de acceso al crédito.

En relación al mercado de tierras y las imperfecciones que éstas presentan en el caso de Honduras; éstas muestran que la estructura concentrada de la tierra distorsiona los precios de la misma; inhibe la formación de nuevas granjas más eficientes y causa un uso ineficiente del capital y los recursos humanos.

Aunque "los mercados de tierras son más elásticos en el sector de pequenas parcelas, desafortunadamente las compra-ventas de este tipo a menudo resultan en aún más subdivisiones de parcelas ya de por sí inadecuadas para soportar una familia".(Un pertil de mercado de tierras en Honduras).

La capacidad de demanda efectiva a su vez es muy limitada ya que el campesino pobre o sin tierras no tiene ingresos suficientes, ahorros o acceso a otros recursos financieros para la compra de tierras, esta situación además debilita su poder de negociación.

El costo y complejidad de procedimientos legales de compra-venta de tierras desestimula este proceso en el caso de Honduras este es más grave debido a la existencia de una gran cantidad de tierras nacionales y ejidales que son ocupadas y cultivadas sin titulo formal. (Un Pertil de Mercado de Tierras en Honduras).

Es importante considerar en el caso de Honduras el apoyo brindado por el AID al proyecto de titulación desde 1982, financiando y disenando la privatización de tierras nacionales y estableciendo un mecanismo funcional de extensión de títulos de propiedad.

"En 1983 USAID asignó 2 millones de dólares en fondos locales (ESF) para establecer' en el Banco Central el fondo para compra de tierras agrícolas ". (Un Pertil de Mercado de Tierras en Honduras).

"Este proyecto de AID para abril de 1988 habla extendido aproximadamente 28,000 títulos a 25,000 familias rurales, y medio millón de hectáreas habian sido delineadas y se hablan preparado mapas completos de los mismos." (Un Pertil de Mercado de Tierras en Honduras).

Ciertamete el esfuerzo de AID por impulsar el proceso de titulación debe tener otros propósitos no explicitos, los cuales podrian estar relacionados al interés de reducir la capacidad organizativa de los campesinos y con esto lograr una relativa estabilidad en el área rural de la 
región, el cual ha sido normalmente el eje básico de los movimientos insurgentes.

\section{El Salvador}

Los mecanismos de titulación y el mercado de tierras en El Salvador están muy relacionados con los efectos directos e indirectos que provoca el proceso de reforma agraria a principios de los ochenta, podemos determinar que tanto las fases I y III de la reforma agraria establecen el mecanismos formal de titulación a partir del pago de la deuda agraria o de la extensión de títulos provisionales o definitivos, esto último especialmente a las unidades parcelarias del Decreto 207.

La modificación que se establece a la fase II de la reforma agraria que deberla afectar las tierras entre 150 a 500 ha. definiendo el límite a la propiedad de la tierra en 245 ha. según la constitución política del '83, genera un mercado de tierras muy dinámico, cambiando la estructura de tenencia de la tierra en forma significativa en la actualidad.

A partir de 1988 con la puesta en marcha del Decreto 839 de Transferencia Voluntaria de Tierras con vocación agropecuaria que trata de ampliar la reforma agraria en lo que era suceptible de afectación de la fase II y a través del mecanismo de compra y venta de tierras; se comienza a establecer un desarrollo del mercado de tierras, pero en función del proceso de reforma agraria. Es así que se crea el comité de organizacines campesinas (COC) que seria el encargado de la asignación de tierras, conjuntamente con la Financiera de Tierras Agrícolas (FINATA).

Para 1989 con el ascenso al gobierno del Presidente Cristiani, el proceso de titulación y mercado de tierras asume un nuevo matiz. EI interés de este gobierno por el desarrollo de las formas individuales de producción no solo se refuerza en las estructuras institucionales de FINATA, sino que se trata también de transformar las estructuras cooperativas de producción creadas por la primera fase del proceso de reforma agraria. Para esto se trata de promover la privatización y parcelación de estas formas de organización de la producción en un primer momento, para luego establecer los mecanismos legales que viabilicen dicho proceso.

A diferencia del caso Hondureno donde los mecanismos de titulación y mercado de tierras se desarrollan sobre la base de tierras de propiedad nacional, en El Salvador dado que estas tierras habian sido incorporadas al proceso de reforma agraria, se trata de modificar las formas colectivas de producción especialmente de las cooperativas y de fomentar la compra-venta de tierras; impulsando para ello la creación del Ban- 
co de Tierras.

La evaluación realizadas por el gobierno, así como los trabajos de Instituciones como la Fundación Salvadoreña para el Desarrollo Económico y Social (FUSADES), contenidos en la propuesta de "Una Estrategia para la Reactivación del Sector Agropecuario en El Salvador" reallzada por Roger D. Norton. Mostraron lo que desde el punto de vista de éstos se consideraba las grandes fallas de la reforma agraria; entre estos mencionaban: (a) la ineficiencia financiera y administrativa de las cooperativas; (b) La mora bancaria incurrida por éstas; (c) La falta de rentabilidad; (d) La creciente deuda agraria, etc. Ante estos problemas la propuesta básica era: "(a) Plantear para la elección de los miembros de las cooperativas, opciones concretas de otras formas de organización empresariales de tipo asociativo, que incluyan cooperativas de servicios más la opción de la parcelación; (b) Darles a los socios el derecho permanente de modificar la estructura de la cooperativa hasta disolverla si fuera necesario. Tal derecho podría se ejercido en cualquier momento; (c) promulgar una reglamentación de derechos y responsabilidades de los miembros de las cooperativas y (d) Sanear la deuda agraria de las cooperativas. (Norton, R. 1989, Págs. 32 y 33).

En sus recomendaciones sobre la fase III de la reforma agraria se consideraba necesario "ampliar la cobertura de la fase III, dándoles a los cooperativistas la opción de vender sus tierras subutilizadas, o cualquier otro componente de sus inmuebles; asímismo, repartir las tierras de las cooperativas abandonadas...no ubicadas en zonas altamente conflictivas y venderlas a los desafectados y los desplazados". (Norton, R. 1989. Pág. 32).

En general la propuesta de parcelación supondría la creación de unidades productivas individuales las cuales supuestamente son más eficientes y rentables, la expansión del acceso a la tierra a los campesinos se harla a través de los mecanismos financieros que posibiliten recursos al campesino para la compra de tierras.

En si la propuesta establece los mecanismos que viabilizarian una trasformación de las cooperativas de la reforma agraria y pospondria indefinidamente la solución al problema estructural de la tenencia y acceso a la tierra, potenciando los mecanismos de mercado de tierras como la alternativa más adecuada.

En esta perspectiva no se puede todavia evaluar los impactos que tendrán estas medidas ya que su aplicación es muy reciente y encuentra una gran oposición de las organizaciones campesinas. Pero sí podemos analizar las tendencias que se presentaron en el marco de la reforma agraria y otras transformaciones en la estructura de tenencia, que nos 
permitan comprender la orientación que llevan explícita o implícitamente estas medidas.

Anteriormente senalábamos los alcances limitados de la reforma agraria en cuanto al área afectada de la tierra, así como de sus beneficiarios; pero también consideramos la importancia que ésta tuvo directa o indirectamente en la transformación de las formas de tenencia de la tierra en EI Salvador.

Uno de los procesos más intensos desarrollados en la década de los '80 está relacionado con el mercado de tierras, éste se deriva de la posible aplicación de la fase II de la reforma agraria, que aunque se limita por el artículo 105 de la Constitución Política (que sehala el máximo de propiedad de la tierra en 245 ha.); éste provoca que "Un total de 39.3 miles de propietarios de tierras vendieran y/o dieran en propiedad a otras personas sus inmuebles, el total de propietarios involucrados de esta forma como oferentes en el mercado de tierras, representa un $17 \%$ del total de propietarios de tierras, los cuales transfirieron en carácter de propiedad, una extensión de $\mathbf{4 0 0 . 4}$ miles de manzanas, tanto en forma de ventas como de cesión de derechos, a parientes escencialmente. El área asi trasferida durante los últimos diez anos, representa un $22 \%$ del área agricola del pais, siempre al margen de las áreas de la reforma agraria". (Ministerio de Agricultura y Ganadería. 1989, pág. 14).

Ciertamente el margen de tres anos que daba la Constitución Política a los propietarios de más de 245 ha. para reducir sus propiedades propicio este dinamismo del mercado de tierras y transferencias.

Un aspecto relevante que muestra la tendencia del mercado de tierras en El Salvador es el referido al número de propietarios involucrados en el proceso y el área transferida. En esta perspectiva el cuadro No. 7 nuestra que "los propietarios involucrados en el proceso de transferencia de tierras de acuerdo al tamano de sus propiedades originales; 39.3 miles transfirieron en una u otra forma su propiedad, en total o parcialmente la mayor proporción de ellas. $64.8 \%$ se ubica entre los que detentaban inmuebles con un tamano hasta las 5 manzanas los cuales sin embargo solo participaron como un $8.6 \%$ del área transferida; los propietarios que cedieron tierras con una extensión de entre 5 y menos de 100 manzanas, constituyeron un $23.9 \%$, aportando un $59 \%$ del área que cambió de propietario; los terratenientes de 100 y más manzanas originalmente, representan solo un $2.3 \%$ de los oferentes en el mercado de tierras, pero sin embargo las tierras transferidas por ellos representan un $32.4 \%$ del total cedido a nivel nacional (Ministerio de Agricultura y Ganadería, 1989 pág. 16 y 17). 
Cuadro No. 6

Número de propletarlos que han venldo y adquirldo tlerras en el perlodo 1978-1987

(Por Reglón)

\begin{tabular}{|c|c|c|c|c|c|}
\hline \multirow{3}{*}{ Región } & \multicolumn{2}{|c|}{ Venta y división } & \multicolumn{3}{|c|}{ Adquisición } \\
\hline & \multirow[b]{2}{*}{$\begin{array}{l}\text { Número de } \\
\text { Propietarios }\end{array}$} & \multirow[b]{2}{*}{$\begin{array}{l}\text { Area } \\
(\mathrm{Mz})\end{array}$} & \multicolumn{2}{|c|}{ Compra } & \multirow{2}{*}{$\begin{array}{c}\begin{array}{c}\text { Otras } \\
\text { Formas }\end{array} \\
\begin{array}{c}\text { Area } \\
(\mathrm{Mz})\end{array}\end{array}$} \\
\hline & & & $\begin{array}{l}\text { Número de } \\
\text { Propietarios }\end{array}$ & $\begin{array}{l}\text { Area } \\
(\mathrm{Mz})\end{array}$ & \\
\hline $\begin{array}{l}\text { I } \\
\text { II } \\
\text { III } \\
\text { IV }\end{array}$ & $\begin{array}{r}7,406 \\
12,016 \\
6,701 \\
13,195\end{array}$ & $\begin{array}{r}93,709.11 \\
81,599.50 \\
71,100.10 \\
154,029.98\end{array}$ & $\begin{array}{l}3,282 \\
7,415 \\
3,350 \\
6,189\end{array}$ & $\begin{array}{r}8,789.71 \\
45,475.60 \\
8,302.99 \\
34,464.77\end{array}$ & $\begin{array}{r}84,919.90 \\
36,123.90 \\
62,797.11 \\
115,565.21\end{array}$ \\
\hline Total & 39,318 & $400,438.69$ & 20,236 & $101,033.07$ & $299,405.62$ \\
\hline
\end{tabular}

Fuente:: PERA. Estudio Nacional del Sector -Agropecuario.

Cuadro No. 7

Propletarlos y área objeto de compra-venta en el mercado de tlerras agricolas, 1978-1979

(por tamano orlginal de propledades)

\begin{tabular}{|c|c|c|c|c|}
\hline \multirow{2}{*}{$\begin{array}{l}\text { Estrato y tamano } \\
\text { de las propiedades } \\
\text { originales }\end{array}$} & \multicolumn{2}{|c|}{ Venta y división } & \multicolumn{2}{|c|}{ Compra } \\
\hline & $\begin{array}{l}\text { No. de } \\
\text { propieta- } \\
\text { rios }\end{array}$ & $\begin{array}{l}\text { Area } \\
(\mathrm{Mz})\end{array}$ & $\begin{array}{l}\text { No. de } \\
\text { Propieta- } \\
\text { rios }\end{array}$ & $\begin{array}{l}\text { Area } \\
(\mathrm{Mz})\end{array}$ \\
\hline $\begin{array}{l}\text { Menos de } 0.5 \\
\text { De } 0.5 \text { a menos de } 1 \\
\text { De } 1 \text { a menos de } 2 \\
\text { De } 2 \text { a menos de } 5 \\
\text { De } 5 \text { a menos de } 10 \\
\text { De } 10 \text { a menos de } 20 \\
\text { De } 20 \text { a menos de } 50 \\
\text { De } 50 \text { a menos } 100 \\
\text { De } 100 \text { y más }\end{array}$ & $\begin{array}{r}9,722 \\
3,987 \\
6,800 \\
4,973 \\
4,736 \\
2,610 \\
4,005 \\
1,568 \\
917 \\
\end{array}$ & \begin{tabular}{|r|}
$10,286.46$ \\
$2,311.85$ \\
$8,956.25$ \\
$12,850.86$ \\
$39,972.18$ \\
$23,341.65$ \\
$86,388.55$ \\
$86,433.61$ \\
$129,897.34$ \\
\end{tabular} & $\begin{array}{r}5,220 \\
3,485 \\
4,180 \\
3,485 \\
1,506 \\
1,048 \\
982 \\
226 \\
104 \\
\end{array}$ & $\begin{array}{r}23,361.38 \\
4,582.58 \\
8,550.64 \\
6,511.59 \\
9,328.02 \\
12,918.44 \\
3,539.34 \\
8,251.37 \\
3,998.71 \\
\end{array}$ \\
\hline Total & 39,318 & $400,438.69$ & 20,236 & $101,033.07$ \\
\hline
\end{tabular}

Fuente: PERA. Estudio Nacional del Sector Agropecuario. 
La aplicación del decreto 839 sobre "La Transferencia Voluntaria de Tierras con Vocación Agropecuaria", en 1988, opera como otro mecanismo de compra-venta de tierras, solo que orientado al fortalecimiento de la reforma agraria.

"Al 30 de junio de 1989, el total de propiedades ofrecidas en venta ascedian a 946 y el número de propiedades negociadas por el Comité de Organizaciones Campesinas (COC) a la misma fecha era de 162, de las cuales 59 habian sido pagadas por un monto de 29,259.024 colones teniéndose asignados en forma asociativa 41 y en forma individual 18; asimismo 20 propiedades habian sido aprobadas por la Junta Directiva de FINATA". (Ministerio de Agricultura y Ganaderia, IX Evaluación del proceso de reforma agraria". 1990, pág. 7).

El proceso de titulación de las parcelas del Decreto 207, el cual se constituye en el mecanismo para establecer la propiedad de las tierras afectadas en la fase III de la reforma agraria mostraba la siguiente situación a 1988: "de las 70,657 parcelas adquiridas a través de FINATA, 18,720 parcelas o sea un $26.5 \%$ poseen títulos definitivos, el número de parcelas con títulos provisionales aún es grande 47,227 que representan el $66.8 \%$ del total. El $6.7 \%$ de las parcelas solamente poseen boletas". (MAG, Tercer Perfil de Beneficiarios del Decreto 207. 1988, pág. 32).

Los mecanismos de titulación y mercado de tierras desarrolladas hasta antes de la aplicación de las políticas del actual gobierno, se inscribian por una parte en el fortalecimiento del proceso de reforma agraria, sea a través de la titulación y otras formas que controlaba FINATA o a través del Decreto 839 que posibilita a las organizaciones campesinas de la reforma agraria desarrollar el mercado de tierras. Por otra parte el dinamismo del mercado de tierras no relacionado directamente con la reforma agraria asume también un rol importante.

Cuadro No. 8

Area adquirlda medlante el Decreto 839

sltuaclón de su pago al 30 de Junlo de 1989

\begin{tabular}{|c|crrr|c|}
\hline \multirow{2}{*}{ Región } & \multicolumn{4}{|c|}{ Decretos } & \multirow{2}{*}{ Total } \\
\cline { 2 - 5 } & 154 & \multicolumn{1}{|c}{207} & 839 & $\mathbf{8 4 2}$ & \\
\hline I & $53,266.8$ & $20,507.8$ & $1,757.1$ & $7,315.4$ & $82,847.1$ \\
II & $46,309.5$ & $13,263.6$ & $1,382.8$ & $4,795.8$ & $65,751.7$ \\
III & $35,631.7$ & $6,634.0$ & 853.9 & $2,792.6$ & $45,912.2$ \\
IV & $63,899.0$ & $13,633.6$ & $1,707.1$ & $8,474.4$ & $87,714.1$ \\
\hline Total & $199,107.0$ & $54,039.0$ & $5,700.9$ & $23,378.2$ & $282,255.1$ \\
\hline
\end{tabular}

Fuente: ISTA. FINATA. 
A partir de junio de 1989 con la nueva orientación del programa coonómico, basado en el ajuste estructural y la privatización de la economla, se trata de impulsar los mecanismos de titulación de propiedades de parceleros del 207 con una mayor fuerza, de tal forma que según datos de FINATA en enero de 1991 se había entregado más de 15 mil titulos en sólo 18 meses, comparado con los 26 mil títulos en los cinco anos de la administración anterior.

Así mismo se comienzan a aprobar en 1991, una serie de leyes orientadas a fortalecer la parcelación de las cooperativas de la reforma agraria y a desarrollar el mercado de tierras. En enero de este ano se aprueba la "Ley Especial para la Transferencia de Inmuebles e Inscripciones de Títulos de Propiedad expedidos por el Instituto Salvadoreno de Transformación Agraria", el cual abre las puertas a la parcelación ya que garantiza la inscripción de propiedades del ISTA en el registro de la propiedad.

En febrero se aprueba la "Ley para el Financiamiento de la Pequena Propiedad Rural" el cual tiene por objeto canalizar recursos financieros provenientes del Estado y de otras fuentes para proporcionar créditos a los campesinos a fin de adquirir tierras en propiedad. Esta ley posibilita también la creación del Banco de Tierras. Asi se formaliza e mercado de tierras.

En abril de 1991 después de una fuerte crítica de las organizaciones campesinas por más de 18 meses y del retiro de los partidos de oposición de la Asamblea Legislativa, es aprobada la Ley del Régimen Especial del Dominio de la Tierra comprendida en la Reforma Agraria" con solo los votos de los diputados del Partido ARENA.

Asl el proceso de transformación de las cooperativas de la reforma agraria tiene ahora una base legal para imponerla.

El proceso de parcelación de las tierras de las cooperativas, tendrlan un Impacto importante en las formas de tenencia de la tierra en los proximos anos, si las cooperativas adoptan el sistema asociativo de particlpación real, planteado en la Ley.

En general en El Salvador, el proceso de reforma agraria con orientación de mercado puede prevalecer en los próximos anos, siempre y cuando esto no se vea modílcado por la nueva Asamblea Legislatlva 0 por acuerdo de la mesa de negociación entre FMLN y el Gobiemo. La presión que ejerzan las organizaciones campesinas será importante en este sentido. Dado que la medida está orientada de una u otra forma a quebrar la capacidad de organización econórnica y política de estas fuerzas que se desarrollaron durante los anos ' 80 . 
El mercado de tierras si bien a pesar de los problemas que pueden enfrentar al igual que en Honduras, puede ser un mecanismos de acceso a la tierra pero que no resuelve escencialmente el problema que más de $\mathbf{2 0 0}$ mil familias sin tierras que existen en la actualidad.

Será necesario pensar en procesos más integrales de organización de la producción y transformación de la agricultura.

\section{Nicaragua}

El proceso de reforma agraria implementado durante la última década, generó una profunda modificación de la estructura agraria del país, a su vez se han desarrollado formas colectivas e individuales de producción, se han configurado cooperativas de producción y de servicios. este conjunto de cambios han propiciado también la formación de una organización agraria de gran importancia en la vida económica y social de Nicaragua; se trata de la Unión Nacional de Agricultores (UNAG).

"La UNAG se sustenta en más de 3,500 organizaciones de base, cooperativas, asociaciones y tiendas campesinas. También estan afiliados 26,618 productores de manera individual, sumando 125 mil el total de afiliados" (Bluklan, Kesse. 1989 Pág.77).

La capacidad organizativa de la UNAG se manifiesta también en su participación con instancias estatales para "la creación de 1,221 cooperativas de producción (CAS) con 25,044 socios, 1,528 cooperativas de Crédito y Servicios (CCS) con 54,125 productores integrados, 112 Cooperativas de Surco Muerto (CSM) con 2,957 miembros y 391 colectivas de trabajo con 3,471 afiliados. Además, ha impulsado como proyecto muy propio la empresa cooperativa ECODEPA con 187 tiendas campesinas y 63,914 miembros. Asimismo, ha impulsado la fundación de 85 Asociaciones con 4,300 productores miembros" (Bluklan, Kesse. 1989. Pág. 77).

La articulación en una organización como la UNAG de diversos tipos de productores y asociaciones de servicios ha sido el resultado de propiciar la iniciativa de los campesinos según sus intereses.

El desarrollo de las formas cooperativas en Nicaragua es de gran importancia, se considera que estas incorporan "alrededor del $20 \%$ de la población económicamente activa en el agro. Son más de 88 mil socios cooperados en las 3,533 diversas formas organizativas afiliadas a UNAG (habria que anadir más de otros 20 mil si se consideraran las cooperativas no afiliadas a la UNAG). Estos socios representan a una población total de casi medio millón de personas $(474,572)$. Entre ellas 
trabajan más de un millón y medio de manzanas $(1,622,564)$ de tierra, es decir alrededor del $20 \%$ de la tierra cultivada" (Hernández Pico, Juan. 1989 Pág. 62).

El amplio avance de las formas cooperativas, asi como su importancla ecomómica y de la organización campesina en Nicaragua, se evidencia en un discurso de Daniel Nunez el cuál sefhaló que el "campesinado cooperativista siembra el 78\% del área del Maiz, el 59\% del área de frijol, el $47 \%$ del área cafetalera, el $42 \%$ del área de frijol dedicada al sorgo industrial, el 32\% del área de arroz tradicional, el $73 \%$ del área ajonjolí y el 125 del área algodonera"(Hernández Pico, Juan. 1989. Pág. 62 y 63).

Estos aspectos evidencian la gran importancia que asume actualmente la organización campesina, asi como la capacidad económica que tienen y el gran potencial de contribuir al desarrollo del agro nicaraguense. Pero esto también puede representar un peligro para sectores, que ha raiz del ascenso de la Unión Nacional Opositora al gobierno, han visto la posibilidad de modificar estas características en función del retorno de tierras a sus antiguos duehos.

Ciertamente la preocupación del anterior gobierno Sandinista no se encontraba en la titulación de tierras de las cooperativas, pero para el campesinado la titulación definitiva significaba "una condición indispensable para sentirse duenos de la tierra, sujetos plenamente productivos, trabajadores, para quienes la tierra se ha socilizado definitivamente, disponiéndolos asi para emplear todas sus energias en contribuir al desarrollo económico del país." (Hernández Pico, Juan. 1989 Pág. 70).

La política del actual gobierno en Nicaragua presenta serios problemas, su interés por trasladar las tierras del Estado a sus antiguos duefos o proceder a su venta al sector privado ha encontrado una fuerte resistencia por parte de las organizaciones campesinas que actualmente poseen estas tierras; esta situación nos lleva a comprender que los procesos de titulación o mercado de tierras que en el pasado no constituian un elemento importante de la política agraria del gobierno sandinista, ahora se pueden establecer como un mecanismo regresivo del proceso de reforma agraria en Nicaragua; todavia no podemos adelantar afirmaciones al respecto mientras no se resuelva el conflicto generado en tomo a estas medidas del actual gobiemo.

\section{Costa Rica}

El problema del acceso a la tierra en Costa Rica al igual que en los demás paises de Centroamérica ha sido un factor de conflictividad social. La política de distribución de tierras en las últimas dos décadas 
se caracterizó por establecer un marco institucional que permitiría una solución más continua a la creciente demanda de tierras y a garantizar la estabilidad política y social en el agro.

La creación del Instituto de Tierras y Colonización (ITCO) a partir de 1962 tenia como propositos: a) Promover la colonización de tierras baldías del Estado para grupos de personas sin tierra; b) La compra de propiedades y su parcelación y venta a campesinos, c) Tener un papel mediador en los conflictos surgidos entre propietarios y los poseedores en precario; y d)contribuir a la conservación y uso adecuado de las reservas de recursos naturales. (Cazanga, José Daniel. 1987. Pág. 189 y 190).

El mecanismo de compra y venta de tierras se desarrolla en Costa Rica desde hace algún tiempo como una altemativa para resolver el problema del acceso a la tierra al campesino; en la década de los 70's el ITCA se fortalece en función de adquirir más tierras y en impulsar proyectos de desarrollo rural.

Bajo esta perspectiva la política de tierras estructurada en un marco institucional "impulsa la iniciativa de regiones de desarrollo, entendidas como un área geográfica en que se proporcionan ciertos recursos y condiciones mínimas necesarias para que el campesino desarrolle sus capacidades productivas y sociales. Esto significarla, además de la distribución de tierras, el acondicionamiento de una infraestructura fisica y social" (Cazanga, José Daniel 1987. Pág. 180).

Una de las dificultades que enfrenta estos programas institucionales es el hecho de que la adquisición de tierras requiere de importantes recursos financieros y de un marco legal $\theta$ institucional que se vaya adecuando a las nuevas situaciones que resulten de un proceso de desarrollo regional o local.

EI ITCO, según el Ex-Presidente Daniel Oduber, "se estima que tiene un millón cuatrocientos mil hectáreas, alrededor del $30 \%$ de las tierras del pals. En veinticinco años ha distribuido 700,000 hectáreas y ha dado tierra a 35,000 colonos". (Oduber, Daniel. 1987 Pág. 38).

El esquema institucional fue presentando debilidades en el marco de la crisis de los anos '80 de tal forma que para 1982 el ITCA se convirtiera en el Instituto de Desarrollo Agrario (IDA), aunque mantiene los mismos objetivos que su predecesora, se operan algunos cambios en relación a los énfasis del quehacer agrario. Uno de los aspectos de prioridad es la implementación de proyectos de desarrollo rural para el cual se recurrió a fuertes apoyos técnicos y financieros de organismos internacionales. 
El problema está que institucionalmente se deberá responder no solamente a proyectos de desarrollo rural sino que a una creciente demandade tierras, de esta forma se senala que, "la lógica de esta política de tlerras pareciera descansar en un quehacer reactivo, que se desencadena a partir de una relación, observada entre mayor desempleo agropecuario - mayor presión por la tierra - mayor financiamiento estatal para atender el problema". (Cázanga, José Daniel. 1987 Pág. 192).

En general si bien en Costa Rica el mecanismo del mercado de tlerras a operado con mayor significación, articulado a proyectos de desarrollo nural; la presión que ejerce sobre la tierra una creciente población y la necesidad del campesino de enfrentar la satisfacción de sus necesidades básicas en un marco de crisis y deterioro de sus condiciones de vida; exige la inversión creciente de recursos financieros y proyectos integrales que lo lleven a una situación de mayor autonomía.

\section{La particlpaclón del campesinado en el proceso de reforma agrarla}

En las últimas dos décadas el desarrollo de las organizaciones campesinas en Honduras y El Salvador han estado asociadas a los procesos de reforma agraria. En Honduras "entre 1973 y 1975, 633 gnupos campesinos de la reforma agraria fueron organizados y asentados en 76,262 has. de tierra, beneficiando a 23,627 familias. Mucha de esta redistribución se logró como resultado de la presión al Gobierno a través de invasiones de tierras sistemáticamente organizadas por las organizaciones campesinas". (Un pertil del Mercado de Tierras Rurales en Honduras).

Las organizaciones campesinas en Honduras han sido de las más estructuradas en América Latina, el fortalecimiento económico de sus formas de organización de la producción (Cooperativas), les posibilitó una amplia imfluencia interna $e$ internacional.

"En 1986 el 75\% de los grupos de la reforma agraria establecidos estaban afiliados a una de las cuatro organizaciones campesinas principales, las organizaciones campesinas más importantes tenian 628 gnupos de campesinos sin tierra, los cuales presionaban al INA y al Presidente de la República por el acceso a la tierra (Un Pertil del Mercado de Tierras Rurales en Honduras).

En El Salvador las organizaciones campesinas se fortalecieron durante los anos '80, especialmente aquellas que se formaron a raíz de la fase I de la reforma agraria. Existen también organizaciones campesinas de cooperativas tradicionales que han ido adquiriendo una mayor 
fuerza en los últimos anos. A pesar de la violencia y la represión ejercida en el marco de la guerra que atraviesa EI Salvador, las organizaciones campesinas han logrado articularse en torno a sus reivindicaciones más inmediatas y en relació a la profundización del proceso de reforma agraria.

En los últimos dos anos las organizacines campesinas articuladas a la Unión Nacional Obrera Campesina (UNOC) y las vinculadas a la Unión Nacional de Trabajadores Salvadorenos (UNTS), han avanzado en marcos de concertación y alianzas a fin de enfrentar más consistentemente la política de ajuste estructural, de privatización y parcelación de tierras de las cooperativas que el Gobierno del Presidente Cristiani a impulsado sin mayor consenso.

Existe en ambos paises (Honduras y El Salvador), a pesar de las políticas en contra desarrolladas por sus Gobiernos o por la influencia del AID, una capacidad de organización campesina que no solamente podria expresarse en respuestas políticas o reivindicativas, sino que también en la conformación de estratégias de desarrollo agrícola que superen los graves problemas que enfrentan actualmente los sectores campesinos.

\section{Reflexlones en torno al apoyo de la organlzaclon y represen- taclón campesina a nivel naclonal y reglonal}

Los mecanismos de titulación y mercado de tierras se presentan con diferentes características en los distintos paises de la región; en el caso de Honduras se estructura en función de tierras estatales y con mayor énfasis en la pequeña parcela con apoyo financiero del AID y un marco institucional; en el caso de El Salvador el dinamismo del mercado de tierras esta asociado directa o indirectamente a la reforma agraria en un primer momento y en los últimos anos a una política deliberada de modificar las formas cooperativas de producción de la reforma agraria y de acentuación como mecanismo básico la compra-venta de tierras para resolver el problema agrario; en Nicaragua se trata de impulsar éstos mecanismos a través de las tierras estatales actualmente en posesión de cooperativas y organizaciones campesinas; y en Costa Rica el proceso institucionalizado desde hace varias décadas ha requerido de amplios recursos financieros y proyectos de desarrollo rural.

El problema básico de estos mecanismos, es que la presión creciente que existe sobre la tierra no logra resolverse dado lo limitado que puede ser el acceso a la tierra a través de la titulación y la compraventa, especialmente en paises que carecen de una importante proporción de tierras estatales suceptibles de ser distribuidas 0 donde existe 
una gran pobreza rural.

Estos mecanismos presentan grandes debilidades sino estan Integradas en una visión de más largo alcance que signifique la transformación de la agricultura y el enfrentar seria y decididamente los orandes problemas del campesinado y el agro de nuestros paises.

Si los mecanismos de titulación y mercado de tierras se orientan en función de una nueva lógica de concentración de la tierra, o pretenden desarticular las capacidades organizativas de los campesinos y sus formas cooperativas de producción es de esperar una mayor profundización de la problemática agraria.

Es importante considerar que durante las últimas décadas se han fortalecido y desarrollado en nuestros paises las organizaciones campesinas, las cuales tienen un papel relevante que jugar en una estratégia de desarrollo económico-social de nuevo tipo.En esta perspectiva las cooperativas, las comunidades y las distintas asociaciones campesinas deben ampliar su capacidad económica tanto para aumentar su productividad y producción, pero asimismo articularse en las distintas fases de transformación y servicios que sus bienes producidos requieren. Esto quiere decir que deben entrar a controlar el procesamiento, almacenaje, comercialización interna y externa de sus productos, deben crear sus estructuras de distribución de insumos y de intermeciación financiera; el objetivo es potenciar la capacidad de estos nuevos agentes económicos a fin de lograr una creciente autonomía y autogestión.

Las cooperativas de producción, a pesar de que estan siendo fuertemente atacadas desde una concepción neoliberal, tienen un gran potencial en un proceso de transformación de la agricultura, es necesario por lo tanto redimensionar sus capacidades y viabilidad como nuevos agentes económicos, adicionalmente son formas de organización de la producción que pueden articular respuestas más adecuadas al problema de la pobreza y el desempleo en el campo.

Esto significa a su vez una redefinición interna de sus lógicas de funcionamiento y organización, de cara a enfrentar los problemas del agro y los retos de la eficiencia y competitividad requeridos en un nuevo entorno nacional e internacional.

La transformación productiva del agro (modernización, nuevas técnicas de producción o la reconstitución y ampliación de técnicas tradicionales según las condiciones específicas de los productores agricolas) debe ser una tarea importante ha asumir por los nuevos agentes económicos (cooperativas, comunidades, etc.).

El acceso a la tierra al campesino seguira siendo un aspecto básico 
a resolver, dada las limitaciones que los mecanismos de titulación y mercado de tierras imponen, habra por lo tanto que buscar formas creativas para incorporar al campesino a la tierra; estas nuevas formas pasan necesariamente por una organización creciente de los campesinos y la aplicación de necanismos legales que sancionen la subutilización de la tierra, pueden haber otras formas, pero la participación del campesino en estas nuevas alternativas de acceso a la tierra debe ser un elemento fundamental.

La cooperación externa especialmente de Europa deberá tomar en cuenta estas nuevas realidades en el agro centroamericano. El apoyo de esta deberá orientarse en diversas líneas de acción.

1. Proyectos de desarrollo de nuevas comunidades campesinas. Lo cual puede involucrar apoyos para compra de tierras, instalación de los asentamientos, creación de infraestructura básica para la producción y las necesidades sociales, créditos para producción y otros servicios básicos relacionados con ella, transformación y capacitación hasta asegurar su autonomia y autogestión.

2. Programas crediticios, sirvan al fortalecimiento de las capacidades productivas y económicas de cooperativas y asociaciones de productores, estas deberan operar fuera del marco institucional del sistema financiero formal; ya que la experiencia de la Cooperación Europea en este campo a través del PROCOOPCA a significado grandes dificultades de acceso al crédito, debido a que se incertaron los fondos en el sistema financiero formal y la banca impuso sus mecanismos tradicionales de garantias que no hacen sujeto de crédito a las cooperativas.

3. programas integrales de apoyo a las cooperativas y asociaciones de productores.

Supondria apoyos en distintas áreas para potenciar estos nuevos agentes económicos, crédito para la producción; recursos financieros para la infraestructura de almacenaje y comercialización, para procesamiento agroindustrial, beneficiado, etc. A todo esto deberá articularse asistencia técnica a fin de formar el capital humano requerido para lograr su capacidad autogestionaria.

4. Programa de desarrollo tecnológico y ecológico se requiere apoyo en procesos tecnológico que garanticen un mejor uso del suelo y una mayor eficiencia en los distintos recursos, esto pasa por la apropiación de nuevas tecnologias, por la formación y capacitación del recurso humano en técnicas de producción acordes a su propio contexto. 
Esto significa también la posibilidad de mejoras en la productividad agricola que fortalecería la capacidad económica de los nuevos agentes sociales.

En lo ecológico, hace necesario programas de apoyo que van desde la ensenanza de la importancia del medio ambiente, hasta la capacidad de preservar y aprovechar adecuadamente los recursos naturales.

En general existen grandes requerimientos para la transformación de la agricultura, pero en este proceso los campesinos bajo sus distintas formas organizativas que poseen actualmente, deben jugar un rol importante, los apoyos deberan ser temporales mientras estos logran su autonomia y autogestión, además de su capacidad de participar e incidir en las decisiones trasendentales de la política económica, agraria o en una nueva estrategia de desarrollo.

\section{BIBLIOGRAFIA}

1. Baumeister, Eduardo. Tendencias de la Agricultura Centroamericana en los años ochenta. FLACSO. 1987, Costa Rica.

2. - Elementos para actualizar la caracterización de la Agricultura Centroamericana. CADESCA. 1991, Panamá.

3. Bluklan, Kesse. Participación Campesina en el Programa de Estabilización y Ajuste Económico en Nicaragua. (Experiencia de la UNAG en 1988/89). Revista Encuentro No. 37/38. UCA 1989 Nicaragua.

4. Cazanga, José Daniel. Algunas Consideraciones Generales en torno a la Dinámica Agraria y la Polltica de Tenencia de Tierras en el Perlodo 19741984. Revista Abra no. 7/8 Julio-Diciembre. 1987. Universidad Nacional. Costa Rica.

5. Comisión de las Comunidades Europeas. Programa Regional de Fomento de las Cooperativas del Itsmo Centroamericano. Primera Exposición (PROCOOPCA). 1988.

6. Fandiño, Juan Mario; Coles Alexander; Caballero, Lily y Stanfield, David. La Titulación de Tierras y la Estructura Social rural en Honduras. Land Jenore Center. University of Wisconsin-Madision. 1986.

7. FAO. Organización de las Naciones Unidas para la Agricultura y la Alimentación. Desarrollo Económico y Social. Potencialidades del Desarrollo Agricola y Rural en América Latina y El Caribe. Roma, 1988.

8. Financiera Nacional de Tierras Agrícolas (FINATA) Plan de Acción 1987. 1986, El Salvador.

9. Hernández Pico, Juan. De Clase __ a Pilar de la Revolución. El Campesinado en la Primera Asamblea Nacional del Movimiento Cooperativo. Revista Encuentro No. 37/38. UCA 1989. Nicaragua.

10. Ley Especial para la Transferencia de Inmuebles e Inscripciones de Títulos de Propiedad expedidos por el Instituto Salvadoreño de Transformación Agraria. 1991, El Salvador. 
11. Ley para el Financiamiento de la Pequeña Propiedad Rural. 1991, El Salvador.

12. Ley del Régimen Especial de dominio de la tierra comprendida en la reforma agraria, 1991, El Salvador.

13. Ministerio de Agricultura y Ganadería (MAG) IX Evaluación del Proceso de Reforma Agraria. 1990, El Salvador.

14. ___ Tercer Pertil de Beneficiarios del Decreto 207. 1988, El Salvador.

15. _. Estudio Nacional del Sector Agropecuario Encuesta sobre uso y tenencia de la tierra. Vol. I. Análisis de Resultados. 1989, El Salvador.

16. . Estudio experimental de adjudicación individual. 1990, El Salvador.

17. Estudio de la situación de las 53 cooperativas declaradas autogestionarias on 1988. 1990, El Salvador.

18. ___ Segundo Pertil de Beneficiarios de la Primera Etapa de la Reforma Agraria (Decreto 154). 1988, El Salvador.

19. Misión Interagencial del Sistema de Naciones Unidas para el examen y análisis de las políticas y estrategias de desarrollo rural del gobierno de El Salvador. La Pobreza Rural en El Salvador: Elementos Básicos para una polftica campesina. Enero de 1986, El Salvador.

20. McReynolds, Samuel; Johnston, Thomas; Gore, Peter y Francis, Joe D. The 1989 El Salvador Agricultural Land use and Land Tenure Study National Cooperative Business Center. 1989, El Salvador.

21. Norton, Roger y Llort, Mercedes. Una estrategia para la Reactivación del Sector Agropecuario en EI Salvador. FUSADES, 1989. El Salvador.

22. Oduber, Daniel. Consideraciones Generales Sobre Ocupación de Baldlos y Tenencia de la Tierra en las Ultimas Décadas. Revista Abra No. 7/8. 1987. Universidad Nacional. Costa Rica.

23. Pelupessy, Wim. El papel de la Agroexportación en la Reactivación Económica de América Central en crisis económica en Centro América y EI Caribe. DEl. 1989, Costa Rica.

24. Sintesis de la problemática sobre tenencia de la tierra. Honduras. mimeo.

25. Stringer Randy. Formland Transfers and the role land banks in Latin America. Land Tenure Center - University of Wisconsin Madison. 1989.

26. Un Pertil de Mercados de Tierras Rurales en Honduras. Mimeo. 